\title{
Evolution of Foreign Language Teaching Methods
}

\section{Ekaterina Mihailovna Kuznetsova}

\author{
Perm National Research Polytechnic University, Perm, 614990, Komsomolskiy pr., 29
}

\section{Doi:10.5901/mjss.2015.v6n6s1p246}

\section{Abstract}

The world globalization sets more stringent requirements to high technical school graduates. Besides professional competences including a certain number of skills a modern specialist must not only be a master in his/her field but in compliance with the Federal State Educational Standards of Higher Professional Education is able to read foreign scientific and technical literature, find out necessary information and apply the results in a proper way in his professional activity both in native and foreign languages. The students' level of mastering the language directly depends on the teaching methods being used.

Keywords: teaching methods, foreign language education, higher education.

\section{Introduction}

Over the centuries there were various methods of foreign language teaching, teaching goals and objectives, schools and teaching approaches. The new teaching methods were developed due to the demand of the state at first and society later in foreign language learning. The scholars tried to find the universal teaching method in different sciences: Philosophy, Psychology, Linguistics etc.

Nowadays the foreign language teacher at high school is to help the students to correct the gaps in their language knowledge at the short time and to teach them using the foreign language as a tool of getting professional knowledge and skills as well. It should be mentioned that the theory and practice knowledge of foreign language teaching at various stages enables the teacher "to see the methodical thought in the broad educational prospect," (Gusevskaya, 2013) and combine different methods and approaches in the work, taking into account their advantages and disadvantages. The following scientists studied the history of foreign language teaching methods: B. Björkman, K. A. Ganshina, N. I. Gez, G. O. Hellekjær, B. Kumaravadivelu, V. E. Raushenbakh, Jack Richards, E. Roulet, L. V. Shsherba, F. C. Sierra. Academician A. A. Mirolyubov made a great contribution into foreign language teaching methods structuring, having published his book "The History of Native Foreign Language Teaching Methods".

According to the analysis of scientific-pedagogical and methodical literature, foreign language learning can be traced back into ancient days. In her book "Studied in Rus. History of Education in Russia" Olga (Kolpakova, 2011) writes that already in 988 A.D. three hundred children were taken "to be taught bookish". The first "bookish teachers" were Greek priests invited specially to teach Russian people the Greek language. The teaching, of course, had a practical nature, as the spreading of the new world outlook (Christianity) required literate people who were able to translate and rewrite liturgical books. The country needed the educated priests speaking not Greek and Latin but the native language understandable to the Russian people. Over the years Russia was turning into the great power with developed trade links. In the $18^{\text {th }}$ century the Russian state needed not only priests but craftsmen, merchants and service class.

\section{Methods of Teaching Foreign Languages}

\subsection{The grammar-translation method.}

During the reign of Peter the Great a great number of educational institutions (special schools, professional and classical schools) were opened. Their aim was not only to train specialists for the state and church but to train skilled workers in various fields (seamen, builders, workmen, translators). It was in these years when the learning of Latin and ancient Greek was followed by the learning of an additional foreign language that became the official educational subject. Latin, however, remaining the standard of systemacity and consistency as before, the teaching of "living" language was the grammar-translation method based on (XVIII-XIX). The proponents of this school V. Gumboldt, D. Gamilton, G. Ollendorf 
considered the language to be a system and since the grammar was the most systematic language level, in teaching the emphasis was made on thorough grammatical system language learning. (Celce-Murcia,1991) Besides, the priority of learning grammar resulted from the prevailing at that time opinion that grammar reflected the logic of thinking and therefore grammar exercises learnt to think.

The cornerstone of education was the written language since only it reflected the true language. Therefore, the texts were the main material the education was based on, P. Gleizer and EH. Pettsol'd (Glejzer, Pettsold , 1912) stated that " The texts for reading were chosen according to their suitability to reflect the grammar material being studied in the best way."( Solontsova, 2009) Some proponents of this method (Heinrich Ollendorf and others) considered the educational text content was to repulse but not to attract schoolchildren for in studying grammar it was important to master the grammar not the text. (Kashina, 2006)

To control the level of understanding grammar the students were to translate from the native language, the sentences not being connected with each other in the meaning:" Lions, bears and elephants are strong", "This bear has a niece and a nephew ", "These camels wrote their lesson of Russian language"(Bik,1890). The vocabulary was considered to be only the illustration for grammar learning. The words were recommended to learn out of context as the isolated units since they were supposed to differ from each other only by sound and graphic but not by the meaning, compatibility etc. (Solontsova, 2009)

In spite of the fact that this method made it possible to understand the grammar of the language being learned thoroughly it couldn't provide elementary communicative skills. The students could hardly express their thoughts and were not able to communicate with the native speakers. Also, translating word for word is wrong because exact translation is not always possible or correct. Moreover, translation is nowadays considered an index of one's language proficiency. (http://hubpages.com/hub/Foreign-language-teaching-methods-approaches)

\subsection{Textual-translation method.}

At the end of the $18^{\text {th }}$ century there appeared a variety of the grammar-translation method -textual-translation method. According to the representatives of this method (J. Jacotot, G. Langenstein, J. Toussaint) the training goal was the students' overall development in reading classical literature. The content and stylistic features of the text became more important.

In some textbooks there was the line arrangement of the texts: in the first line there was a text in a foreign language, in the second line there was its transcription and the third line contained its literal translation, with the grammar structure being the same as in the foreign language. Having repeated the text after the teacher many times and having read the transcription the students were to analyze the translation and propose the appropriate literature translation. Thereby, the pronunciation was practiced, the analysis, vocabulary and grammar learning was carried out. Unlike the representatives of the grammar-translation method the proponents of the textual-translation method didn't study the grammar in detail they used and analyzed only the material that was in the text. Therefore, the grammar teaching was irregular. The vocabulary, as before, was formed by the mechanical learning of separate words and texts in the foreign language. The representatives of this method, however, made a great contribution in the language teaching methods having used for the first time the translation from the native language into the foreign one.

We quite agree with the conclusions of the authors of the book "Foreign Language Teaching Methods at the Secondary School" (Gez et al ,1982) that for the first time in the history of teaching methods the translation methods of the foreign language teaching had serious drawbacks. Firstly, they were badly directed towards the language acquisition as communication means even for reading training. The main task was only general education, it being understood as the development of logical thinking as a result of grammar learning and as the general development as a result of accidental grammar learning during text studying. Secondly, the characteristic feature of these methods was form and content separation. In the grammar-translation method all attention was focused on the form, with the content being disregarded. In the textual-translation method the texts were not always available since the grammar was studied unsystematically and the students were badly prepared to its perception. Thirdly, the language learning was based on the grammar and logic identification, on the dead language recognition as the ideal and on the disregarding of the living languages specific features.

\subsection{Direct methods}

At the end of the $19^{\text {th }}$ century the translation methods were replaced by the direct methods of foreign language teaching. Their main goal was mastering the oral communication. In their book (Foreign Language Teaching Methods at the 
Secondary School) the authors state that besides the existing social-economic conditions the search for new teaching methods and approaches was caused by the convergence of such sciences as Psychology and Linguistics. In Linguistics there appeared a new psychological school headed by a linguist and psychologist Hermann Steinthal. The school itself didn't influence the teaching methods but it became the intermediate link between the logical school (it studied the language in its relation to thinking and knowledge) and the neogrammarian school (it considered the language as an individual psychophysical and psychophysiological activity). The neogrammarian school made a great influence on the language teaching theory. The scholars of this school studied the similarities in the language based on the psychological associations in the mind of the person speaking. The achievements in Psychology also influenced the direct method development. In the works devoted to the language the founder of the experimental psychology W. Wundt, being a follower of the associanism, stated that the speech was a kind of activity where acoustic and motoric sensations were of great importance. During speaking the sentence arises in the man's consciousness as an integral product. It is this thought that is traced in the natural method proponent concept who considered the sentence to be the center of an oral statement. Another method was represented by the Würzburg school studying the man's thinking and its forms. The scholars of this school stated the proposition was neither connected with speech nor with sensory perception. The speech was to be taught by mechanical way. The foreign language teaching methods were also influenced in some way by Geshtalt psychology. The scientists of this school considered the primary and foremost learning task to be the understanding the whole but not the separate elements. They paid great attention to the imitation during teaching, especially language teaching.

Hence, it follows that the Pedagogics couldn't stay at the same place. It required the reforms meeting the social necessities of that time for foreign language fluency. The new school, however, was created by theorists-practicians having no sufficient proof for scientific explanations of their methods. They were guided only by their teaching feeling.

There developed the direct teaching methods among them natural approach, direct, audiovisual and aural-oral methods.

The most distinguished representatives of the natural method M. Berlitz, F. Gouin, M. Walter thought that to learn a foreign language quickly and thoroughly was possible only by reconstructing the verbal environment. Despite some differences their teaching concepts had something in common namely the total exclusion of the native language from the foreign language immersion process. "If we give the meaning of a new word, either by translation into the home language or by an equivalent in the same language, as soon as we introduce it, we weaken the impression which the word makes on the mind" (Billows, 1961) The main goal was practical oral speech acquisition. The teaching was to proceed by intuition like the child mastered his native language.

Up to date in some countries there are schools where teaching is based on Berlitz's methods. He believed that it was necessary to exclude the native language entirely from the foreign language teaching and moreover it was quite essential to teach thinking in a foreign language. The lesson based on his methods consists of the following basic stages: explaining the new vocabulary by means of objects (or their pictures), gestures, explanations in a foreign language etc.; the teacher's conversation with the audience or with himself; conversations or short descriptions of the pictures by the students. Berlitz advised to teach the grammar first as the vocabulary and not systematically but occasionally. The abstract concepts were to be explained by revealing their meanings from the context. Berlitz's system pursued the specific practical goals.( Raushenbakh, 1971)

The other representatives of this school F. Gouin and M. Walter adhered to the same teaching concepts but they introduced new techniques for creating the natural verbal environment.

In the field of Pedagogics Gouin followed J. Pestalozzi's ideas and his doctrine about sense-visual perception and in the field of Psychology he followed H. Steinthal's ideas who considered the language processes to be the reflection of man's mental activity.( Raushenbakh, 1971)

Having studied the teaching and methodical literature we found out an interesting fact that while observing the children Gouin revealed that in the native language the children accompanied their playing with toys with comments in the chronological sequence. It was this case that caused the creation of his own original methods that was based on the following principles: the natural language teaching is connected with the man's needs to express his feelings; the teaching basis is to be a sentence but not a word; the most reliable and effective perception is the auditory one therefore the primary teaching means is to be oral speech but not reading and writing. The center of any sentence is the verb that is the key to its understanding. The new feature of his system is that the vocabulary semantization is carried out by means of "internal visualization" that is based on the logic sequence of the actions being made.

Walter's characteristic feature was that he accompanied each lesson with playing organizing a kind of theatre performance where the students were the actors. Considering the sense perception of the surrounding world to be very important he tried to bring the teaching closer to the students' acquaintance with the country they learned the language 
of. While teaching the German language in Scotland he made his classroom to be looked like a pub.

Following the principles of associative psychology he stated that it was much easier to remember the material if it was organized by creating the associations. As L. P. Solontsova stated: "It should be noticed that M. Walter for the first time in the history of linguistics arranged the vocabulary into groups as the means for its learning and remembering. He suggested organizing the words into different groups: synonyms and antonyms, words belonging to the same topic, paronymous words."

Nowadays the teaching methods specialists consider his methods of describing pictures to be interesting. In describing a picture he advised to emphasize the forms of the object, its physical characteristics (size, form, colour etc.), the actions with this object and its usage.

Despite the new approaches into the teaching methods, however, the natural method was severely criticized by the linguists and psychologists because of having insufficient scientific basis. At the turn of the $20^{\text {th }}$ century the direct method of foreign language teaching was derived from the natural method. The main advantage of this teaching method unlike the natural one was that it was developed by such prominent scientists as O. Jespersen, H. Sweet, P. Passy, V. Fiester. The direct method was called so because its proponents identified the foreign language word directly with its concept without using the native language word.

It should be noted that these two methods had much in common. Both the natural and direct methods were aimed at practical language skills that were limited to teaching the oral communication skills but the direct method followers broadened the concept "practical skills" by adding the teaching of reading.

The direct method as well as the natural one eliminated the native language usage and translation. According to the authors of the textbook "Foreign Language Teaching Methods at the Secondary School" the denial to use the translation was caused by the prevailing at that time linguistic theory that stated each language reflected different world outlook. Therefore, the translation in the strict sense of this word was impossible since each nation had its own paradigm.

The vocabulary selection for the lessons was determined by the topics and communication situations taken from the real life and the grammar material to be learned was to correspond with the existing at that time language norm. The scientists who developed this method advised to use induction at the lessons i.e. the students were to observe the language model usage at speech and to find the language patterns by themselves. The teacher, thereafter, arranged these language patterns into a certain system by means of rules and instructions. (Shchukin,2004)

The essential difference between the direct and natural methods was that the former restricted to some extent the language material not only the vocabulary but grammar and phonetics as well. The phonetic material was for the first time scientifically selected and significantly broadened. (Gez et al,1982)

Unlike the direct method spread in Europe its features were somewhat different in Russia. Its proponents didn't so strongly object to the native language usage. They allowed its using as a means of the word semantization and understanding control. L. V. Shcherba wrote the following about the direct method: "Though the direct method intention to make the foreign language knowledge totally independent from the native language and to prevent it from the influence of the latter is quite legitimate and methodically right in its essence nevertheless it absolutely fails in practice: the environment is stronger all these tricks the direct method dictates and the native language negatively affects the students' foreign language. The requirement to manage without the native language often causes the great time, energy and ingenuity expenditures that are quite wasteful in most cases since the complete understanding usually comes after the student's finding his own equivalent in the native language. Moreover this requirement makes it quite impossible to explain the students more subtle language phenomena that leads to the devaluation of foreign language learning from the educational point of view." (Shsherba,1974)

A. A. Mirolyubov in his works also quoted the famous teaching specialists and scientists confirming the necessity of foreign language usage. E. Bik stated:" I am far from rejecting the benefit of the students' acquaintance with the living speech but I can't, however, agree with the native language removal at the beginning of the foreign language learning because while rendering the meaning of a given phrase from the language being learnt into the native one we develop the ability to the unconscious learning and thus contribute to the language spirit understanding and especially speech patterns that become noticeable only with the native language assistance." The author also quotes the great Russian educator K. D. Ushinskiy that in translating from the foreign language it is not enough to understand the thought being translated thoroughly, to catch all its shades but it is by far more important to find the appropriate expression in the native language. Mind, intellect, imagination, memory, speech are to be trained simultaneously. According to A. A. Mirolyubov the "Russian version" development of the direct method is also explained by the Russian and West-European language difference. The similarity of West-European languages made it possible to develop education without using the students' native language. It was impossible to do it in Russia.

The direct method representatives made considerable contribution in the foreign language teaching methods. 


\subsection{Neodirect methods}

In the $20^{\text {th }}$ century there appeared the new variants of the direct method-neodirect ones that were divided into the Palmer's oral method, audiolingual and audiovisual methods. All these methods were based on the basic positions of direct method but each representative of the new method tried to renew and improve his approach of foreign language teaching.

In his teaching concept Harold Palmer, an English educator and teaching specialist shared the linguistic ideas of sociological school ( $F$, de Saussure, A. Meilett), behaviourist psychology (E. Thorndike, J. Watson) and pragmatical pedagogics (J. Dewey). Each of them in V. E. Raushenbakh' opinion didn't recognize the language and thinking integrity, considered the language to be an abstract phenomenon. This viewpoint at the language promoted the consciousness in the language learning wasn't almost used and was replaced by mechanical methods that were to cause the appropriate physiological (e.g. speech) reflexes. (Raushenbakh, 1971)

Palmer being the proponent of the intuitive language learning entirely shared the direct ideas about the students' immersion into the language medium. He thought that many failures in foreign language teaching were caused by the fact that the students were required to answer the questions by all means therefore at the beginning of the language learning he introduced the so-called "latent period" (up to two months) when the students were only to listen and immerse into the foreign speech developing the aural memory. The repetitive drilling is the basis of any language learning and it is referred to both the separate words and phrases and sentences. In his opinion the perceptual memorizing and repetitive drilling made it possible to avoid mistakes.

Palmer's main contribution was the teaching content rationalization. For the first time he structured the vocabulary being learned selecting it on the basis of linguistic and teaching principles: 1) frequency- a lexical unit usage rate compared with other ones, with the different meanings of one and the same word being considered separately; 2) structural combinatory- the lexical unit ability as a sentence element (ergon) to combine with others; 3) concretion- the lexical units meaning concrete concepts should be included in the basic vocabulary in the first place as they could be semantized by means of visual aids; 4) proportionality- the proportion of different parts of speech in the basic vocabulary must be the same as in the natural language; 5) appropriateness- if it belongs to the same semantic group as the previously selected words. (Gez et al,1982)

The requirements to the text selection that are used in the teaching process are also rather notable. The text content must be of interest to the students and correspond to their age, they must contain only the things known to the students and the subject texts must be preferred due to their greater suitability to the oral speech mastering. As far as the vocabulary and language material is concerned the texts must consist of strictly selected vocabulary and at the initial level they must contain up to $95 \%$ of these words, with the meaning of the unknown words being understood by the students from the context.

Palmer made some rationalization into the grammar teaching as well. In his work "A Hundred of Substitution Tables" he selected the main sentence types most frequently used in the language and created the substitution tables on their basis. (Palmer,1923)The major goal of these tables was to help structuring secondary constructions on the basis of vocabulary unit combinatory. The students were to make up sentences quickly. Such drillings were repeated a lot of times and the students mastered a great number of sentences. Unlike the direct method representatives Palmer tried to arrange the exercises into a definite sequence i.e. system. He proposed to create a system of exercises considering the following student action sequence: perception, recognition, semi-free reproduction and free reproduction. It was a serious advance in the teaching methods. (Solontsova, 2009)

Palmer's ideas can be found in the modern methods of foreign language teaching. The idea of substitution tables is widely used now, both the grammar and the vocabulary substitution tables being quite popular. The idea of type sentences as one of the speech development basis was used by N. S. Koblents in his "synthetic method". A. P. Starkov and G. E. Vedel used oral introduction course based on Palmer's ideas in the Soviet schools in the $30 \mathrm{~s}$ of the $20^{\text {th }}$ century.

Palmer's oral method considerably influenced the audiolingual and audiovisual method development.

The audiolingual method representatives, a linguist-structuralist $\mathrm{Ch}$. Freeze and a teaching method specialist $\mathrm{R}$. Lado shared the ideas of the famous at that time linguist L. Blumfield about the language. Blumfield considered the speech communication to be divided into the stimulus (influence) and the "reaction' (back action)(Blumfield, 1968). This method goal, therefore, according to Freeze and Lado was the development of necessary automatic reactions on the appropriate stimuli. The usage of perception auditory channel, multiple listening and repetition of foreign structures after the teacher results in such speech automatic reaction formation.

The representatives of this teaching method paid special attention to the sound (phonetic) aspect of the language 
being learned. Following Blumfield's proposition that different sounds had different meanings in human speech;" learning this specific sound-meaning correspondence meant the language learning" (Blumfield) Ch. Freeze and R. Lado came to the conclusion that "the language basis was its sound system and structures". According to this statement the language teaching course should contain everything related to the language sound system (sounds, intonation, rhythm, stress, pauses). (Solontsova, 2009)

The culture of the country which language was learnt was also of great importance since regarding the language as the reflection of history, culture and mode of life of the people who spoke that language R. Lado thought that foreign language learning was inseparably connected with the penetration into the culture of its people as they were inseparable and couldn't be understood separately. One cannot understand other nation (and its language) without acquiring its system of ideas that in its turn is possible only using the language of this nation as its native speakers use other ideas. The penetration into the nation culture, the knowledge of its system of ideas has both educational and practical meaning. (Belyaev,1965)

Simultaneously with the audiulingual method in the USA there was developed an audiovisual method in France whose developers were considered to be R. Gouberina, P. Rivenc, C. Gougenheim, R. Michea. The representatives of this method advanced no new original methodological concepts except the wide usage of audial and visual aids. The vocabulary selection of material determined the goals set before this method: teaching the language of everyday communication in oral form and in undertime. Though this method was aimed at the adults its elements in the form of situational dialogues reflecting the real life of the country which language was used, its culture and traditions can be found in modern textbooks teaching foreign languages.

The advantages of these two methods are the opening of the first language laboratories, the wide usage of new modern equipment and visual aids increasing the learner motivation in foreign language learning. The texts and dialogues about the history, culture and traditions of the country which language is learned expand the outlook and encourage the learners' speech activity.

In spite of these contributions, audionlingualism was also criticized in many ways. First, its theoretic foundation was attacked as being unsound both in terms of language theory and learning theory by Chomsky's theory of TG grammar; second, the practical results fell short of expectations and students were often found to be unable to transfer skills acquired through Audiolingualism to real communication outside the classroom. Therefore, it ignores the communicative competence in teaching practice (LIU Qing-xue \& SHI Jin-fang, 2007).

\subsection{Communicative method}

In the 40 s of the last century the Soviet teaching authorities realized the inefficiency of certain foreign language aspect teaching and the necessity of development a new linguistic theory that would include the teaching of each speech activity aspect. First of all the learning consciousness was gradually increasing. The psychological and pedagogical researches convincingly showed that the most important condition of the skill formation efficiency was the consciousness in its mastering action comprehension but not the mechanical skill acquisition, conscious but not intuitive language mastering.( Gez et al,1982)

As the goal definition changed ("language teaching"- "speech teaching"- "speech activity teaching"- and at last "communication teaching") the teaching system was also to change. (Passov,1991) After thorough reconsideration and analysis of the existing methods E. I. Passov suggested a new communicative method. The peculiarity of this method was the attempt to make the foreign language teaching process closer to the real communication process where the teaching process was the communication process model.

In his book "The Communicative Method of Teaching Foreign Speaking" E. I. Passov (Passov,1991) revealed in details the notion of communicativeness. In his opinion the main features of communicativeness were: 1) speech orientation of the teaching process that causes speech-thinking activity that is the basis of the communicative teaching process.

2) individualization of the speech activity teaching i.e. taking into account each individual attributes of the learners: their abilities, their skills to fulfill speech and learning activity and most of all their personality attributes. In teaching foreign speech activity the individual reaction is possible only if a speech task facing the learner will correspond to his needs and interests as an individual. To cause the appropriate response, therefore, it is necessary to take into account the individual and personal features: life experience, outlook, spheres of interests, hobbies etc.

3) functionality. Language proficiency skill formation takes place as a result of speaking when a speaker has a certain speech task. The speech tasks set determine the topics and communication speech situations that are thoroughly selected. It is very important to eliminate the translation from the skill development process since the acquisition of 
speech facilities system in one language should be formed by exercising with this system inside it but not by comparing speech facilities system of another language.

4) situatedness of teaching. Situatedness makes it possible to reconstruct the communicative reality and thus to arouse interest by speaking authenticity.

5) novelty. Novelty provides the necessary development of speech ability, the ability to paraphrase and the ability to the unprepared speech.

Today Communicated method can be seen as a set of core principles about language learning and teaching, as summarized above, assumptions which can be applied in different ways and which address different aspects of the processes of teaching and learning. Some focus centrally on the input to the learning process. Thus content-based teaching stresses that the content or subject matter of teaching drives the whole language learning process. Some teaching proposals focus more directly on instructional processes. Others, such as competency-based instruction and text-based teaching, focus on the outcomes of learning and use outcomes or products as the starting point in planning teaching. Today Communicated method continues in its classic form as seen in the huge range of course books and other teaching resources that cite Communicated method as the source of their methodology. In addition, it has influenced many other language teaching approaches that subscribe to a similar philosophy of language teaching. (Richards, 2001)

\section{Research Question}

The study answered the research question: Which teaching method was the most suitable for studying English as a second foreign language?

\section{Context of the Study}

The research was conducted with 60 students of technical departments from Perm National Research Polytechnic University during the second semester for the academic year 2012/2013. Students were divided into 3 groups, the size of the groups was similar $(20,20,20)$. The three groups were different from one another in terms of the teaching method type: grammar-translation method (GTM), direct method (DM) and communicative method (CM).

The GTM group was taught and learnt English based on the grammar-translation method approach. Written language was superior to spoken one. Increasing of students' vocabulary was by the means of memorization of long lists of vocabulary with their equivalents in the students' native language.

The DM group was taught according to direct method technique. Russian language was excluded from the learning process. The majority of time was avoided to oral communication such as topics, dialogs and role plays. As grammar was taught inductively, students should determine a regularity of a grammatical phenomenon usage relying on studied drills.

And in the $\mathrm{CM}$ group training was in accordance with communicative method strategy. The aim of language teaching was to develop communicative competence. All exercises were connected with the necessity of real communication situation reconstruction.

\section{Results}

After 3 months of implementing the study, all students (three groups) had the similar final exam in compliance with the ederal State Educational Standards of Higher Professional Education. The average score in the GTM group was 3.5, in spite of the aims set this method couldn't meet the requirements to the language proficiency level. Regardless the evident, practical training goals and high results in reading and translation teaching the grammar-translation method was not directed towards the language mastering as communication means. The average score in the DM group was 4.3 and this result showed that students could keep the conversation but relaying on the learnt phrases and drills. A great difficulty students had in translating a specialized professional text since the direct method implied an intuitional language teaching approach, students hardly ever could give an equivalent of a highly specialized term in their native language. And the highest result with the average score 4.7 showed the CM group. Students could communicate their thoughts rather clearly, they didn't feel any difficulties expressing their ideas. But there were certain imperfections also. And the first one was that students didn't pay attention on the grammatical side of their speech stressing on WHAT I want to say but not HOW. And being taught to communicate orally, a weak point of the students in this group was writing an essay. The majority of the students followed the spoken style didn't focus on the structuring their thoughts according to the plan of the essay. 


\section{Discussion and Conclusion}

So, as far as we can see during all its history the foreign language teaching methods changed a lot of times emphasizing reading, translating or audition or combining these processes. Each method possesses its own certain importance and answers the specifically set pedagogical tasks e.g. grammar and textual-translation methods are better suited for grammar material training before tests, direct methods are more appropriate for language medium immersion and for reconstructing the real communication situations, visual aids assist to represent visually and to systemize the unknown material. The teaching literature review makes it possible to state that nowadays there is no an ideal, universal method yet that would enable to cover all the aspects in such a short time given to the foreign language learning in a technical high school. The combination of the existing methods known and the teacher's qualification, therefore, enables to make the lessons interesting and effective.

On the basis of the foregoing we can conclude that during the whole history of foreign language teaching methods development methodologists and teachers highlighted different types of speech activities (reading, listening, translation) focusing on a particular era goal. In addition, each method has its own specific value and responds to specific pedagogical objectives set.

Thus, historiographical analysis of foreign language teaching methods has allowed identifying ways to integrate different methods in the practice of language education. In our point of view, for students studying at the technical departments it would be useful applying grammar- textual-translated methods for an explanation and revision of the grammar materials at the pre- text stage. Direct and communicative methods can be used to stimulate communication situations in the language environment. And using of visualization tools helps to present and organize new material and to create an outer support of speech acts.

\section{References}

Belyaev B.V. Essays on the psychology of teaching foreign languageshttp://gigabaza.ru/doc/73625-pall.html

Bik E.A The Analitico-Synthetic Method of Foreign Language Teaching / Russkaya shkola. - 1890. - №5.

Billows F. L. The techniques of language teaching. London: Longman, 1961, DOI: 10.2307/321360

Blumfield L. Language. M.: Progress, 1968.

Foreign Language Teaching Methods at the Secondary School: textbook/Gez N. I., Lyakhovitskij M. V., Mirolyubov A.A. i dr. -1982.

Glejzer P., Pettsold EH., German textbook ch. II. Izd. 10. - S. - Peterburg, 1912.

Gusevskaya N.YU. Language Teaching Theory and Methods. Proceedings ZabGu. 2013. №6 (53)

Harold E. Palmer. The oral method of teaching languages. Cambridge,1923

Hub pages. ESL Methods - English Language Teaching. http://hubpages.com/hub/Foreign-language-teaching-methods-approaches

Kashina E.G. Traditions and innovations in the methodology of a foreign language teaching. Student's book. - Samara: Izd-vo « Universgrupp», 2006.

Kolpakova. O. Studied in Rus. History of Education in Russia. Izdatel'stvo: Belyj gorod God: 2011

Kumaravadivelu B. Undestending language teaching. Taylor \& Francis e-Library, 2008.

LIU Qing-xue, SHI Jin-fang. An Analysis of Language Teaching Approaches and Methods -Effectiveness and Weakness. US-China Education Review, Jan. 2007, Volume 4, No.1

Passov E. I. Passov E. I. Communicative Method of Teaching Foreign Speaking - 2-d ed. - M.: Prosveshhenie, 1991.

Raushenbakh V.EH. The Abstract of the Basic Foreign Language Teaching Methods in the 1-20 ${ }^{\text {th }}$ Centuries- M.: high school, 1971.

Shchukin A.N. Teaching foreign languages: Theory and practice. Training manual for teachers and students. M.: Filomatis, 2004.

Shsherba L. V. The Foreign Language Teaching at School: General Methodic Questions.-2nd ed.-M., 1974.

Solontsova L.P. A textbook for students of pedagogical specialties and foreign languages teachers of different types of educational institutions. Pavlodar: PGPI, 2009.

Richards, Jack; Rodgers Theodore. Approaches and Methods in Language Teaching. Cambridge: Cambridge University Press, 2001, DOl: http://dx.doi.org/10.1017/CBO9780511667305

Celce-Murcia, Marianne. Language Teaching Approaches: An Overview. Teaching English as a Second or Foreign Language. Heinle \& Heinle Publishers. 1991. 